\title{
Effect of blood transfusion in low birthweight infants
}

\author{
R. O. ROBINSON, M. FUJIMURA, P. HOWAT, AND D. M. SAlisbURY \\ From the Department of Paediatrics, John Radcliffe Hospital, Oxford
}

SUMMARY 143 fresh blood transfusions were given to 32 low birthweight babies, 28 of whom had hyaline membrane disease. The arterial or central venous pressure was raised by a blood transfusion if before transfusion the mean arterial pressure was less than $35 \mathrm{mmHg}$ or if the diastolic central venous pressure was less than $-0.5 \mathrm{mmHg}$. There was no effect of blood transfusion on $p \mathrm{H}$. It therefore appears either that metabolic acidosis in hyaline membrane disease is not caused by poor peripheral perfusion or that blood transfusion does not increase peripheral blood flow in this condition. The safety of the procedure is assessed.

A low red cell mass and blood volume have been reported in association with hyaline membrane disease (Inall et al., 1965; Cassady, 1966; Brown et al., 1975). In addition, Usher et al. (1975) have presented data which suggest that a decrease in red cell mass is associated with an increase in severity of and mortality from hyaline membrane disease (HMD). It seems logical therefore, as advocated by Phibbs (1969), to augment tissue perfusion and oxygenation in HMD with small serial blood transfusions. We report our experience with this method of treatment.

\section{Patients and methods}

Observations were made on 32 babies of less than 34 weeks' gestational age (range 26-33 weeks) whose mean birthweight was $1142 \pm 296 \mathrm{~g}$ (range 650$2000 \mathrm{~g}$ ). Blood was drawn from a panel of donors all of whom were screened for blood communicable diseases including cytomegalovirus. Where possible, cross-matching was performed before transfusion. When it was judged that blood transfusions were urgently required, unmatched $\mathbf{O}$ or unmatched blood of the same group as the baby was given. An attempt was made, depending on the availability of donors, to restrict the number of donors for each baby. 143 transfusions were given to the 32 babies. The distribution of numbers of donors and the total volume of blood $/ \mathrm{kg}$ transfused in individual babies are shown in Tables 1 and 2 respectively.

Blood transfusions were given for hypotension (systolic arterial pressure $<40 \mathrm{mmHg}$ ) or metabolic acidosis (-base excess $>8 \mathrm{mmol} / \mathrm{l}$ ), or to replace diagnostic blood loss $(>10 \%$ of the estimated blood

Received 17 January 1977
Table 1 Numbers of donors for individual babies

\begin{tabular}{cc}
\hline No. of donors & No. of babies \\
\hline 1 & 12 \\
2 & 8 \\
3 & 3 \\
4 & 2 \\
$>4$ & 3
\end{tabular}

Note: It was not possible to determine in 4 babies the number of donors.

Table 2 Volume of blood given to individual babies

\begin{tabular}{cl}
\hline Volume blood transfused $(\mathrm{ml})$ & No. of babies \\
\hline $0-10$ & 8 \\
$11-20$ & 8 \\
$21-30$ & 5 \\
$31-40$ & 2 \\
$41-50$ & 4 \\
$51-60$ & 2 \\
$>60$ & 3 \\
\hline
\end{tabular}

volume). Blood gases were estimated 4-hourly or less. In a few babies an intravascular $\mathrm{Po}_{2}$ electrode provided continuous $\mathrm{PaO}_{2}$ estimations. Continuous records of arterial pressure (17 babies) and central venous pressure ( 9 babies) were made using Elcomatic transducers and displayed on a Devices M 19 multichannel recorder.

Zero reference point was taken at the midpoint of the anteroposterior transthoracic diameter. For the purposes of determining the effect of blood transfusion on the blood gases and $p \mathrm{H}$, only estimations 2 hours before or after transfusion, between which there had been no alkali therapy or adjustment of ventilator settings, were analysed. With these exclusions 78 transfusions were available for analysis from the 32 babies. For control purposes 108 pairs 
of blood gas estimations between which no blood transfusions were given were analysed from the same babies.

For the purposes of examining the effect of blood transfusion on arterial or central venous pressure, values at 5-minute intervals were extracted from the record manually. The mean of the 5-minute values before transfusion was compared with the mean of the values for the hour after transfusion. For control purposes the mean of the hour starting 2 hours before transfusion was compared with the hour immediately before transfusion.

\section{Results}

Changes in arterial pressure during the 2 hours before transfusion appear to be random (Fig. 1). The effect

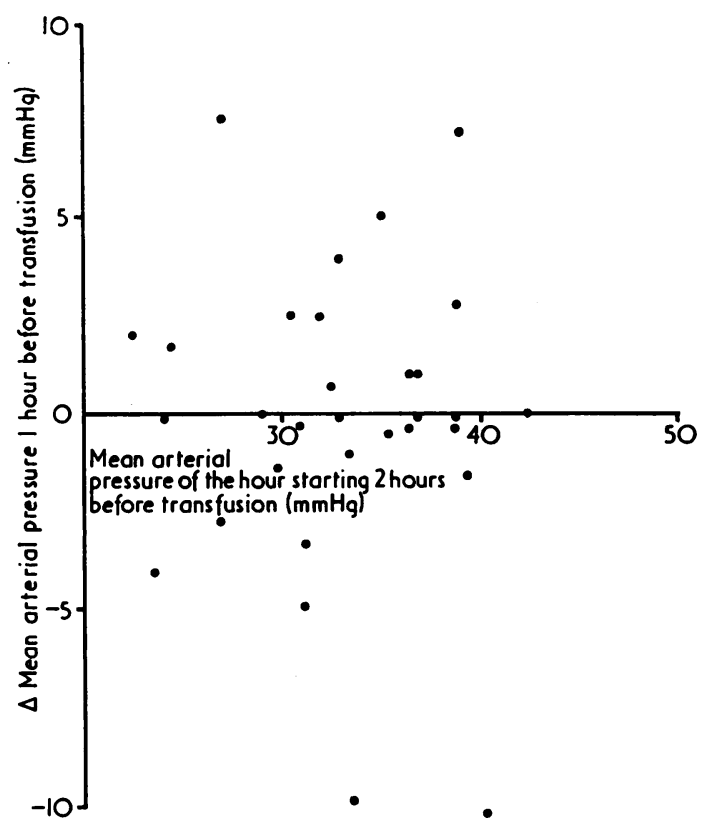

Fig. 1 Change in mean arterial pressure 2 hours before transfusion.

of a blood transfusion was to impose order on the random change (Fig. 2) $(\mathrm{P}<0.001)$. It will be seen from the point at which the regression line crosses the ordinate that the effect of a blood transfusion was to raise the mean arterial pressure if it was less than $35 \mathrm{mmHg}$. Conversely, if the arterial pressure was more than $35 \mathrm{mmHg}$ it appears that the effect of a blood transfusion was to lower it. Similarly, the change in diastolic central venous pressure after transfusion is shown in Fig. 3. Unlike the systolic

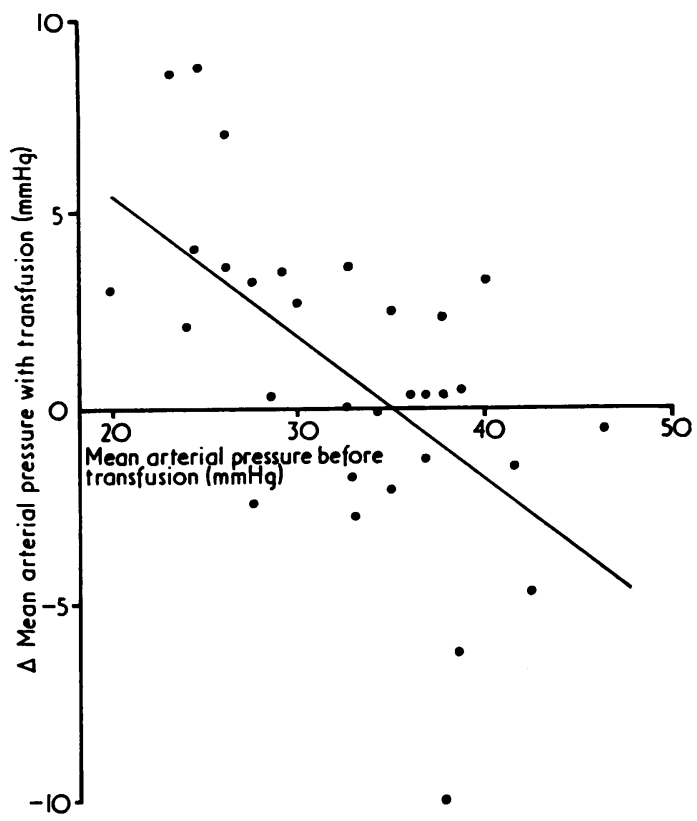

Fig. 2 Change in arterial pressure caused by a transfusion $(r=0 \cdot 5, P<0 \cdot 001)$.

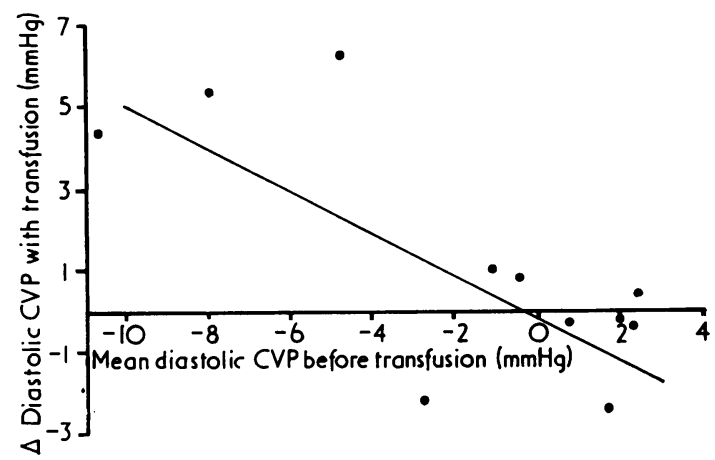

Fig. 3 Change in diastolic central venous pressure $(C V P)$ caused by a transfusion $(r=0 \cdot 74, P<0 \cdot 01)$.

central venous pressure in which there was no clear effect of blood transfusion, a low diastolic central venous pressure $(<-0.5 \mathrm{mmHg})$ was raised by a blood transfusion $(\mathrm{P}<0 \cdot 01)$.

Changes in hydrogen ion concentration occurring without alkali therapy or adjustment of ventilator settings are shown in Fig. 4. It will be seen that there was a tendency for a displaced hydrogen ion concentration to return to $50 \mathrm{mmol} / \mathrm{l}(\mathrm{pH} 7 \cdot 30)$. Changes in hydrogen ion concentration with a blood transfusion (Fig. 5) did not differ significantly from 


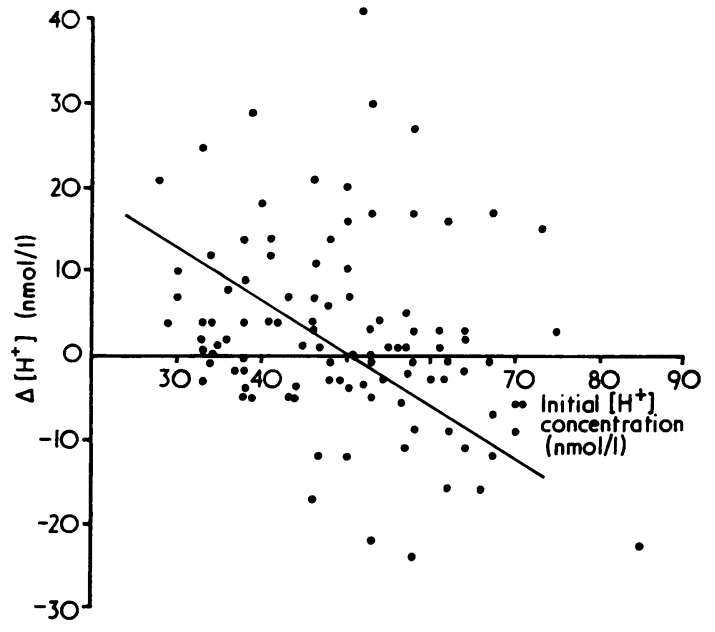

Fig. 4 Change in hydrogen ion concentration occurring without alkali therapy or adjustment of ventilator settings $(r=-0.4169, P<0.001)$.

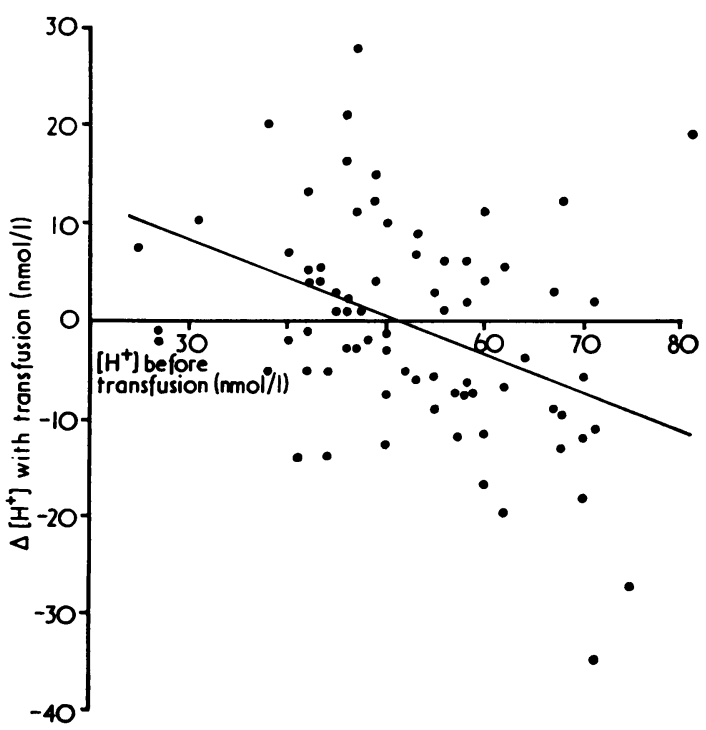

Fig. 5 Change in hydrogen ion concentration with a transfusion $(r=-0.42, P<0.001)$.

changes effected by homoeostasis. Similarly, there was no additional effect of blood transfusion on changes in $\mathrm{PaO}_{2}$ or $\mathrm{PaCO}_{2}$.

\section{Discussion}

Operation of a walking donor system has been criticized for failing to comply with the blood trans- fusion service requirements (Oberman, 1975). In over 200 transfusions given in our Special Care Baby Unit we have not identified any transfusion reactions or cases of graft-versus-host disease.

Although within wide limits arterial pressure appears to be maintained independently of the red cell mass or blood volume (Brown et al., 1975; Robinson et al., 1977), the arterial pressure if low was raised by blood transfusion. Red cell mass values were available in 12 of the babies, but could not be used to predict the response of arterial pressure to blood transfusion. This supports our suggestion made elsewhere (Robinson et al., 1977), that the actual red cell mass is less important than the appropriate red cell mass for a particular baby in a particular situation. In this context, from the response of the diastolic central venous pressure to blood transfusion, it appears that the pressure of the venous system filling during diastole may be a useful indicator in the clinical situation of the adequacy of the circulating blood volume.

Our data do not support the suggestion that blood transfusion reverses metabolic acidosis. It may be argued that our failure to show an effect may be attributed to the method of analysis, but this is unlikely since with the same method we were able to show a clear effect on hydrogen ion concentration of bicarbonate and THAM administration. Another possible reason for our failure to show an effect may be that insufficient blood was given. However, we have not been able to identify an increasing effect on $p \mathrm{H}$ of subsequent blood transfusions. It appears therefore that either metabolic acidosis associated with HMD is not attributable to poor peripheral perfusion, or that blood transfusion does not increase peripheral blood flow in this condition.

It is noticeable that in the last few years we have used much less alkali than previously in the treatment of babies with HMD. This may be a consequence of more effective methods of assisted ventilation. In the 32 babies studied in this paper 28 had hyaline membrane disease but only 8 of these received any alkali therapy. Moreover, in 7 of these 8 alkali was only given within 2 hours of birth for acidosis associated with severe birth asphyxia. Thus, in giving blood transfusions with the object of increasing peripheral perfusion and combating metabolic acidosis we may have been attempting to treat a condition that was already disappearing for different reasons. In order to assess the effects of blood transfusion on metabolic acidosis we had to exclude those babies in whom some other major change in therapy had taken place over the hours of study. It might be the case that blood transfusion was only effective in terms of metabolic acidosis in those babies for whom ventilator settings had been 
altered and who were therefore excluded from analysis. This seems inherently unlikely, since the ventilator settings were altered for several different reasons, for instance if a baby's clinical condition was improving as well as when it was deteriorating. However, we cannot altogether discount the possibility that metabolic acidosis already present may be reversed more rapidly with the addition of blood transfusion to effective ventilation. Only a prospective and controlled trial could answer this question. P.H. was in receipt of a grant from the Medical Research Council; D.M.S. was in receipt of a grant from the Sir William Coxen Trust Fund; M.F. was a British Council Scholar. Babies were under the care of Drs. J. D. Baum, B. Bower, H. Ellis, M. Moncrieff, D. Pickering, and Professor J. P. M. Tizard. We are indebted to Miss P. Townshend and nursing colleagues for help and co-operation, and to Professor Tizard for his help in preparation of the manuscript.

\section{References}

Brown, E. G., Krouskop, R. W., McDonnell, F. E., and Sweet, A. Y. (1975). Blood volume and blood pressure in infants with respiratory distress. Journal of Pediatrics, 87, 1133-1138.

Cassady, G. (1966). Plasma volume studies in low birth weight infants. Pediatrics, 38, 1020-1027.

Inall, J. A., Bluhm, M. M., Kerr, M. M., Douglas, T. A., Hope, C. S., and Hutchison, J. H. (1965). Blood volume and haematocrit studies in respiratory distress syndrome of the newborn. Archives of Disease in Childhood, 40, $480-484$.

Oberman, H. A. (1975). Replacement transfusion in the newborn infant. A commentary. Journal of Pediatrics, 86, 586-587.

Phibbs, R. (1969). What is the evidence that blood pressure monitoring is useful? Problems of Neonatal Intensive Care Units, p. 81. Report of the fifty-ninth Ross Conference on Pediatric Research. Ross Laboratories, Columbus, Ohio. Robinson, R. O., Fujimura, M., Howat, P., and Salisbury, D. M. (1977). Red cell mass in low birth weight infants. Journal of Perinatal Medicine (in press).

Usher, R. H., Saigal, S., O'Neill, A., Surainder, Y., and Chua, L-B. (1975). Estimation of red blood cell volume in premature infants with and without respiratory distress syndrome. Biology of the Neonate, 26, 241-248.

Correspondence to Dr. R. O. Robinson, Department of Neurology, Albert B. Chandler Medical Center, University of Kentucky, Lexington, Kentucky 40506, USA. 